\title{
Comparison of physicochemical, sorption and electrochemical properties of nitrogen-doped activated carbons obtained with the use of microwave and conventional heating
}

\author{
Justyna Kaźmierczak-Raźna ${ }^{1} \cdot$ Paulina Półrolniczak ${ }^{2} \cdot$ Krzysztof Wasiński $^{2} \cdot$ Robert Pietrzak $^{1} \cdot$ Piotr Nowicki $^{1}$ D
}

Received: 30 November 2018 / Revised: 4 January 2019 / Accepted: 10 January 2019 / Published online: 1 February 2019

(c) The Author(s) 2019, corrected publication 2019

\begin{abstract}
A series of new nitrogen-doped activated carbons has been obtained via the reaction with urea and chemical activation of Polish brown coal. In order to obtain nitrogen groups bonded in different ways to the carbonaceous matrix, the modification with urea was performed at two different stages of processing, i.e. precursor or char. Additionally, the effects of conventional or microwave heating on the physicochemical parameters, sorption abilities as well as capacitance behaviour of the carbons prepared were tested. All the materials under investigation were characterized by elementary analysis, surface area measurements as well as estimation of the number of surface functional groups. The sorption properties of the materials were tested towards methylene blue at temperature of $25^{\circ} \mathrm{C}$. Moreover, symmetric supercapacitors containing organic electrolyte and prepared carbons were tested in Swagelok ${ }^{\circledR}$ type cells by using CV, GCD and EIS methods. Depending on the variant of preparation, the final products were micro/mesoporous nitrogen-doped activated carbons of well-developed surface area ranging from 617 to $1117 \mathrm{~m}^{2} / \mathrm{g}$, showing acidic or intermediate acid-base character of the surface and different contents of nitrogen functional groups varying from 1.0 to $5.6 \mathrm{wt} \%$. The results obtained in this study showed that introduction of nitrogen and chemical activation of brown coal led to activated carbons with very good sorption capacity toward organic dyes as well as good electrochemical parameters. The specific capacitance was achieved up to $86 \mathrm{~F} / \mathrm{g}$ for N-doped carbon obtained by microwave carbonization followed by chemical activation with potassium carbonate.
\end{abstract}

Keywords Brown coal · Chemical activation · Activated carbons · Incorporation of nitrogen · Adsorption from liquid phase $\cdot$ Electrochemical capacitors

\section{Introduction}

The nitrogen-doped carbonaceous materials can be obtained via different ways, however, the most often applied method is thermal treatment of carbonaceous precursor in the presence of nitrogen supplying agent such as urea, melamine or ammonia (Nowicki and Pietrzak 2011; Liang et al. 2004; Vargas et al. 2013; Seredych et al. 2009; Grzybek et al. 2008; Shirahama et al. 2005). Very popular method is also

Piotr Nowicki

piotrnow@amu.edu.pl

1 Adam Mickiewicz University in Poznań, Faculty of Chemistry, Laboratory of Applied Chemistry, Umultowska 89b, 61-614 Poznań, Poland

2 Institute of Non-Ferrous Metals, Division in Poznań, Central Laboratory of Batteries and Cells, Forteczna 12, 61-362 Poznań, Poland pyrolysis and/or activation of plastics containing nitrogen species in their structure, e.g. polyacrylonitrile, polyamides or polyurethane (Sullivan et al. 2012; Hayashi et al. 2005; Zaini et al. 2010). The third variant of nitrogen-enriched materials preparation is deposition of amines and imines of any order on the surface of chemically or physically activated carbons (Gholidoust et al. 2017). Depending on the applied variant of modification, the carbon materials obtained are characterized by different contents of nitrogen, different types of functional groups and their different positions in the carbonaceous structure (Chen et al. 2003; Boudou et al. 2006; Nowicki et al. 2010).

Regardless of the method of nitrogen-doped activated carbons preparation, the processes are based on the use of conventional heating (Nowicki et al. 2008, 2009; Kazmierczak-Razna et al. 2017; Jurewicz et al. 2008), whose main disadvantages are non-uniform heating of the samples and what is more important, the necessity of using high temperatures, 
which can lead to destruction of earlier introduced nitrogen functional groups (Kazmierczak-Razna et al. 2015). A very interesting and attractive alternative seems to be the use of microwave energy for heating, which offers uniform heating of the whole sample volume. Moreover, microwave heating is based on direct conversion of electromagnetic energy into heat so thermal treatment can be carried out at a lower temperature and for a shorter period of time than when conventional heating based on convection and radiation is used (Jacob et al. 1995; Remya and Lin 2011; Jones et al. 2002).

Taking the above into consideration, the main purpose of the present study was to obtain a series of $\mathrm{N}$-doped activated carbons via the reaction with urea and chemical activation of Polish brown coal as well as to compare the influence of conventional and microwave heating on the physicochemical parameters, sorption abilities and capacitance behaviour of the carbons prepared.

\section{Experimental}

\subsection{Preparation of activated carbons}

The precursor of activated carbon was the Polish brown coal (B) from the Konin colliery. The starting material was milled and sieved to the grain size of $0.5 \mathrm{~mm}$, demineralised (D) by concentrated $\mathrm{HCl}$ and $\mathrm{HF}$ according to the Radmacher and Mohrhauer method (Radmacher and Mohrhauer 1956) and subjected to further treatment including enrichment in nitrogen (U), pyrolysis $(\mathrm{P})$ and chemical activation (A) in different sequences: (1) reaction with urea followed by pyrolysis and activation (BUPA samples) and (2) pyrolysis followed by reaction with urea and activation (BPUA samples). The unmodified activated carbons (BPA samples) were used as a references. The sample codes and the preparation details are outlined in the scheme presented in Fig. 1.

Incorporation of nitrogen (U): $50 \mathrm{~g}$ of carbonaceous material was impregnated with urea at the weight ratio of $1: 1$, dried to constant mass at $110{ }^{\circ} \mathrm{C}$ and then subjected to thermal treatment for $1 \mathrm{~h}$, at $350{ }^{\circ} \mathrm{C}$, in nitrogen flow (100 mL/min).

During pyrolysis $(\mathrm{P})$ the samples were heated in two variants - in conventional resistance furnace $(\mathrm{Pc})$ as well as in microwave muffle furnace $(\mathrm{Pm})$. This process was performed under nitrogen atmosphere (flow rate $170 \mathrm{~mL} / \mathrm{min}$ ). The samples were heated at the rate $10^{\circ} \mathrm{C} / \mathrm{min}$ from room temperature to final pyrolysis temperature of 600 (in case of microwave furnace) or $700{ }^{\circ} \mathrm{C}$ (in case of conventional furnace), and maintained for 30 or $60 \mathrm{~min}$, respectively.

The chars obtained were next impregnated with potassium carbonate solution (at the weight ratio of $2: 1$ ), dried to constant mass at $110{ }^{\circ} \mathrm{C}$ and then subjected to thermal treatment in nitrogen atmosphere (flow rate $330 \mathrm{~mL} / \mathrm{min}$ ). The impregnated samples were heated $\left(10^{\circ} \mathrm{C} / \mathrm{min}\right)$ from room temperature to final activation temperature of $700{ }^{\circ} \mathrm{C}$ (in microwave furnace, Am) or at $800{ }^{\circ} \mathrm{C}$ (in conventional furnace, Ac), kept at the final activation temperature for 15 or $30 \mathrm{~min}$, respectively, and then cooled down in nitrogen flow. The products of activation were subjected to two-steps
Fig. 1 Scheme of preparation of the activated carbon samples

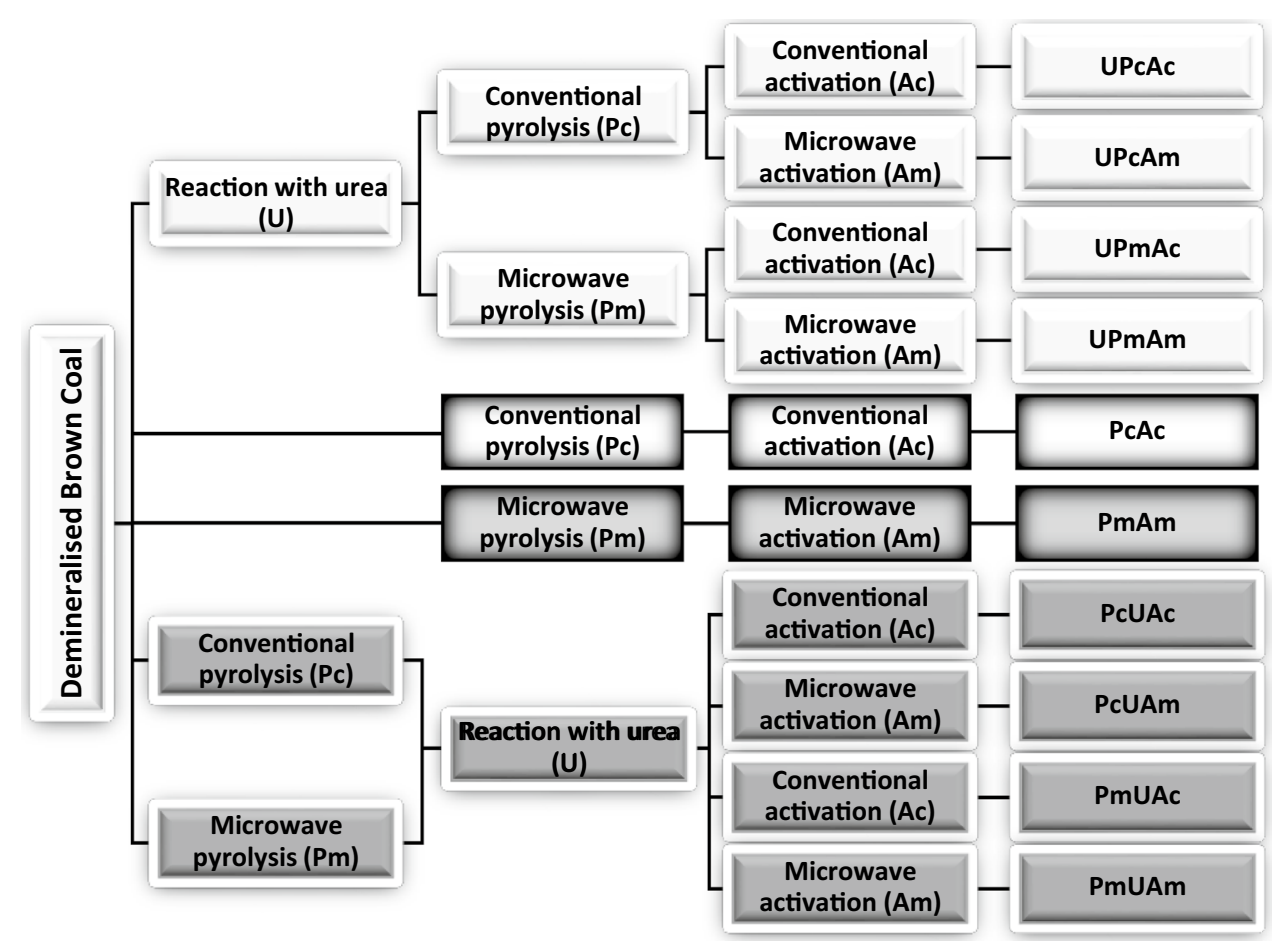


washing procedure, with $5 \%$ solution of hydrochloric acid and later with demineralised water until free of chloride ions.

\subsection{Sample characterisation}

Elemental analysis (C, H, N, S) of the precursor, chars and activated carbons obtained was carried out using the CHNS Vario EL III analyser provided by Elementar Analysensysteme $\mathrm{GmbH}$, Germany. The ash content for all materials under investigation was determined according to the DNS ISO 1171:2002 standard, according to which the dried sample in a form of powder was burned in a microwave furnace at temperature $850^{\circ} \mathrm{C}$, for $60 \mathrm{~min}$.

Characterization of the pore structure of activated carbons was based on the nitrogen adsorption-desorption measured at $-196{ }^{\circ} \mathrm{C}$ on Autosorb iQ surface area analyser. Prior to the isotherm measurements, the samples were outgassed at $150{ }^{\circ} \mathrm{C}$ for $8 \mathrm{~h}$. On the grounds of results of these measurements BET surface area, total pore volume and average pore diameter were determined. The total pore volume was calculated at a relative pressure of approximately $p / p_{0}=0.99$ and at this relative pressure all pores were completely filled with nitrogen. Average pore sizes and pore distributions (Figs. 2, 3) were calculated from the adsorption branches of isotherms using the BJH method. Additionally, micropores volumes and areas were determined by the t-plot method.

To evaluate the content of oxygen functional groups of acidic and basic character the Boehm method was applied (Boehm et al. 1964; Boehm 1994). Volumetric standards of $\mathrm{NaOH}(0.1 \mathrm{M})$ and $\mathrm{HCl}(0.1 \mathrm{M})$ were used as the titrants.
The $\mathrm{pH}$ of materials was measured by means of $\mathrm{pH}$ meter manufactured by Metrohm Ion Analysis (Switzerland) equipped in Unitrode Pt1000 (combined glass pH electrode), using the following procedure: a portion of $0.4 \mathrm{~g}$ the sample of dry powder was added to $20 \mathrm{~mL}$ of demineralised water and the suspension was stirred overnight to reach equilibrium. After that time, $\mathrm{pH}$ of the suspension was measured.

\subsection{Adsorption studies}

Methylene blue adsorption was determined according to the following procedure. Samples of the prepared activated carbons in the same portions of $0.025 \mathrm{~g}$ with the particle size $\leq 0.09 \mathrm{~mm}$ were added to $0.05 \mathrm{~L}$ of methylene blue solution with initial concentrations in the range from 0 to $200 \mathrm{mg} / \mathrm{L}$ and the suspension was stirred to reach equilibrium for $12 \mathrm{~h}$ at temperature of $25^{\circ} \mathrm{C}$. After the adsorption equilibrium had been achieved, the solution was separated from the sorbent by centrifugation. The dye concentrations in the solution before and after adsorption were determined using a double beam UV-Vis spectrophotometer (CaryBio100, Varian) at a wavelength of $665 \mathrm{~nm}$. All experiments were made in triplicate. The equilibrium adsorption amounts (mg/g) were calculated according to the following formula:

$\mathrm{q}_{\mathrm{e}}=\frac{\left(\mathrm{c}_{\mathrm{i}}-\mathrm{c}_{\mathrm{e}}\right) \cdot \mathrm{V}}{\mathrm{m}}$

where $c_{i}$ and $c_{e}(m g / L)$ are the initial and equilibrium concentration of the dye, V (L) is the volume of the dye solution, and $\mathrm{m}(\mathrm{g})$ is the mass of activated carbon used, respectively. The equilibrium data were analysed by the Langmuir and Freundlich models.
Fig. 2 Pore size distribution in activated carbons obtained via conventional activation

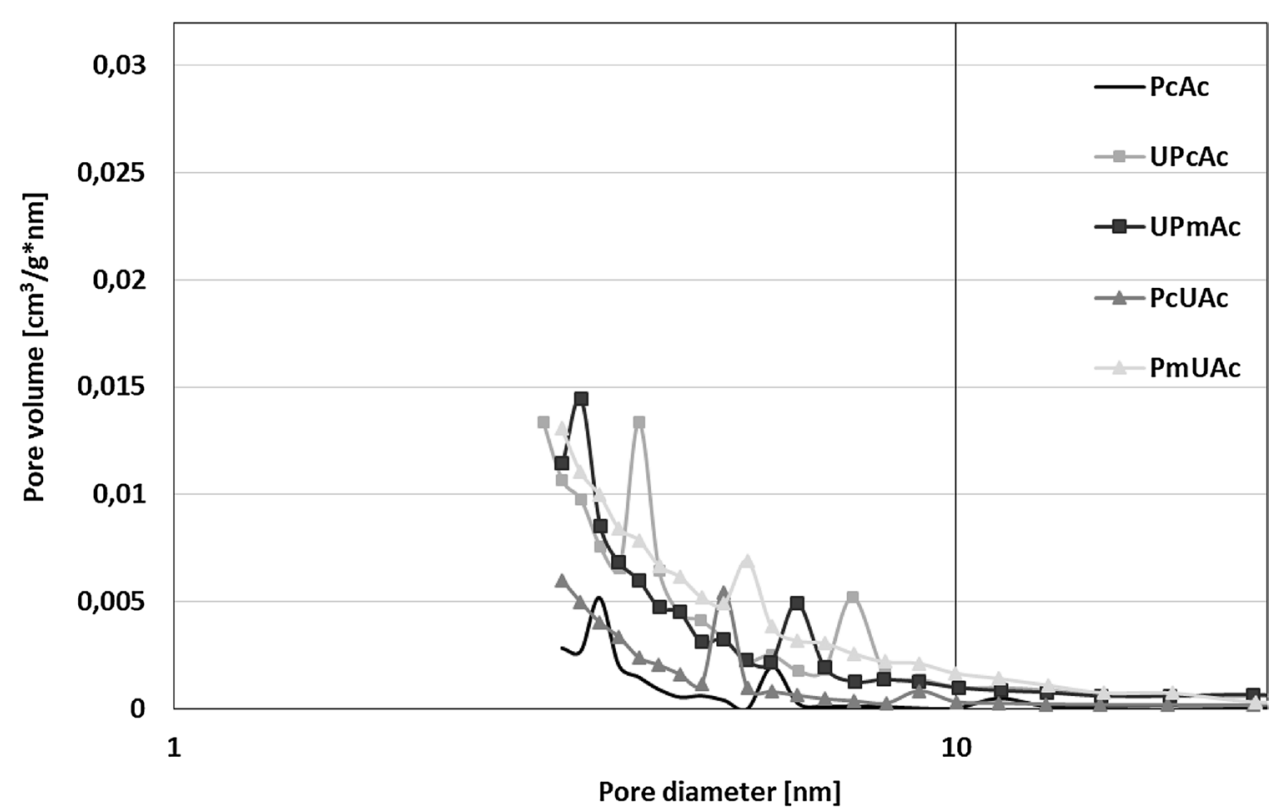


Fig. 3 Pore size distribution in activated carbons obtained via microwave activation

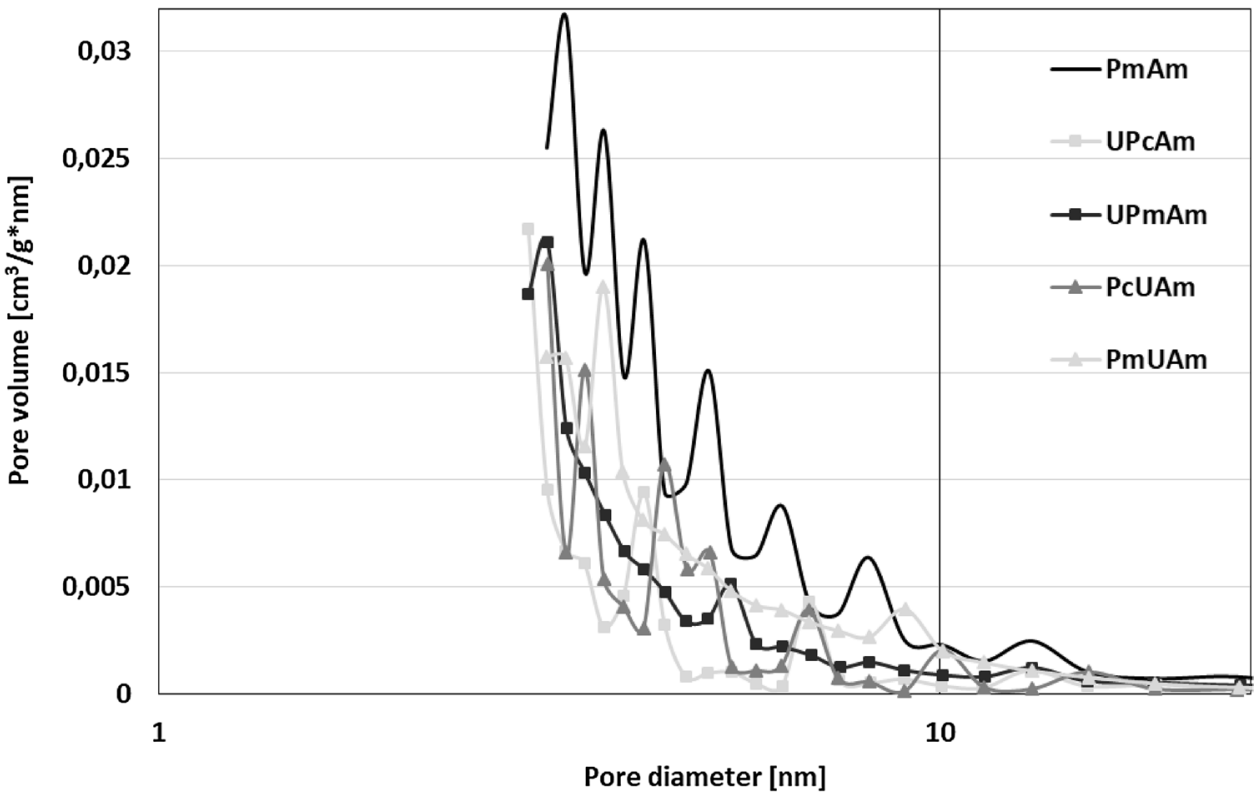

\subsection{Electrochemical study}

Prepared carbons were mixed with polymer binder (poly(vinylidene fluoride-co-hexafluoropropylene), KynarFlex ${ }^{\circledR}$, Atofina) and acetylene black $\left(\mathrm{C} 65\right.$, Timcal $\left.{ }^{\circledR}\right)$ in a mass ratio 80:15:5. Next, $N$-methylpirolidone (>99\%, VWR) was added slowly. The obtained slurry was mixed for $20 \mathrm{~h}$. The homogeneous, viscous slurry was then casted onto aluminum current collector using the doctor blade technique. The prepared electrodes were vacuum dried at $105^{\circ} \mathrm{C}$ for $24 \mathrm{~h}$. Symmetric two-electrode Swagelok ${ }^{\circledR}$ type cells with electrodes were assembled in argon filled glovebox (MBraun, $\mathrm{H}_{2} \mathrm{O}<0.5 \mathrm{ppm}, \mathrm{O}_{2}<0.5 \mathrm{ppm}$ ). $1 \mathrm{M}$ tetraethylammonium tetrafluoroborate ( $>99 \%$, Aldrich) in acetonitrile (>99.8\%, Aldrich) was used as an electrolyte. Electrochemical experiments were performed with the application of multichannel potentiostat-galvanostat VMP-3 (Biologic). The following techniques were applied: cycling voltammetry (CV) at scan rates from 1 to $100 \mathrm{mV} / \mathrm{s}$; galvanostatic charge/ discharge (GCD) at current density ranging from 0.1 to 10 in Amper per mass of two electrodes $(\mathrm{A} / \mathrm{g})$ and electrochemical impedance spectroscopy (EIS) at the frequency range from $100 \mathrm{kHz}$ to $1 \mathrm{mHz}$ and amplitude $10 \mathrm{mV}$. The operation voltage of supercapacitors were fixed to $2.7 \mathrm{~V}$. All results were calculated as the specific capacitance values and expressed in Farads per mass of active material per one electrode $(\mathrm{F} / \mathrm{g})$.

\section{Results and discussion}

\subsection{Characterization of the activated carbons}

Analysis of the data presented in Table 1 shows that the precursor used for the study is characterized by very high content of mineral matter (ash) as well as organic non-carbon impurities, mainly oxygen. Demineralization of the starting brown coal with the concentrated hydrochloric and hydrofluoric acids removes almost $84 \%$ of the mineral substance from its structure and leads to small but notable changes in the elemental composition. The demineralized sample had a bit higher content of carbon, nitrogen and sulphur than the initial coal. Demineralization also leads to small decrease in the content of hydrogen and oxygen calculated from the difference.

As indicated by the data presented in Table 2, pyrolysis and activation of the demineralized brown coal (both in conventional and microwave furnace) cause significant changes in its structure. Thermochemical treatment brings a
Table 1 Proximate and elemental analysis of starting and demineralised coal (wt $\%$ )

\begin{tabular}{llllllll}
\hline Sample & Ash & Moisture & $\mathrm{N}^{\text {daf } *}$ & $\mathrm{C}^{\text {daf }}$ & $\mathrm{H}^{\text {daf }}$ & $\mathrm{S}^{\text {daf }}$ & $\mathrm{O}^{\text {diff** }}$ \\
\hline B & 18.8 & 9.7 & 0.6 & 61.6 & 6.2 & 1.7 & 29.9 \\
D & 3.1 & 0.0 & 1.0 & 65.6 & 5.5 & 1.8 & 26.1 \\
\hline
\end{tabular}

* Dry-ash-free basis

** Determined by difference 
Table 2 Elemental composition of activated carbons (wt\%)

\begin{tabular}{lllllll}
\hline Sample & Ash & $\mathrm{N}^{\text {daf } *}$ & $\mathrm{C}^{\text {daf }}$ & $\mathrm{H}^{\text {daf }}$ & $\mathrm{S}^{\text {daf }}$ & $\mathrm{O}^{\text {diff** }}$ \\
\hline PcAc & 2.8 & 0.5 & 95.5 & 0.1 & 0.0 & 3.9 \\
PmAm & 2.3 & 1.1 & 90.4 & 0.2 & 0.4 & 7.9 \\
UPcAc & 1.3 & 1.3 & 94.4 & 0.2 & 0.1 & 4.0 \\
UPcAm & 1.3 & 4.2 & 88.0 & 0.3 & 0.3 & 7.2 \\
UPmAc & 1.8 & 1.3 & 94.4 & 0.1 & 0.0 & 4.2 \\
UPmAm & 1.4 & 4.4 & 87.8 & 0.4 & 0.4 & 7.0 \\
PcUAc & 0.5 & 1.0 & 93.3 & 0.1 & 0.0 & 5.6 \\
PcUAm & 0.9 & 5.6 & 86.3 & 0.3 & 0.2 & 7.6 \\
PmUAc & 2.7 & 1.2 & 95.4 & 0.1 & 0.0 & 3.3 \\
PmUAm & 1.7 & 5.4 & 87.3 & 0.4 & 0.3 & 6.6 \\
\hline
\end{tabular}

* Dry-ash-free basis

** Determined by difference substantial increase in the content of $\mathrm{C}^{\mathrm{daf}}(24.8-29.9 \mathrm{wt} \%)$, accompanied by a considerable decrease in the content of the non-carbon elements, with the exception of nitrogen. These changes are mainly induced by high temperature of the processes, in particular that of the activation process. Upon heating the least stable fragments of the coal structure (e.g. methylene, oxygen, sulphur bridges) break, leading to formation of side products of pyrolysis and activation, rich in hydrogen, such as water, hydrogen sulphide or hydrocarbons. Relatively small changes in the content of $\mathrm{N}^{\text {daf }}$ suggest that brown coal contains nitrogen in the form of thermally stable functional groups. However, it should be emphasized that all changes are much greater in the variant with conventional heating (PcAc sample).

As follows from further analysis of the data collected in Table 2, a similar situation takes place for samples modified with nitrogen at the precursor (UPA samples) or char stage (PUA samples). All the samples obtained via activation at $800{ }^{\circ} \mathrm{C}$ in a conventional furnace (Ac) are characterized by very high carbon content ranging from 93.3 to $95.4 \mathrm{wt} \%$. For analogous samples activated in a microwave furnace (Am) the content of $\mathrm{C}^{\text {daf }}$ is about 7-8 wt\% lower. All the nitrogen-enriched activated carbons show very low content of $\mathrm{H}^{\text {daf }}$, which is most probably a consequence of gasification of the hydrogen-rich and amorphous fragments of coal structure as well as progressing aromatisation of carbonaceous matrix during pyrolysis and activation processes. Moreover, the activation with $\mathrm{K}_{2} \mathrm{CO}_{3}$ in a conventional furnace brings almost total removal of sulphur from the carbonaceous structure. Depending on the variant of heating applied during the activation step, the $\mathrm{N}$-doped activated carbons differ significantly in the content of nitrogen and oxygen. Samples UPcAc, UPmAc, PcUAc and PmUAc obtained via activation in a conventional furnace show almost 3-5 times lower $\mathrm{N}^{\text {daf }}$ content than the analogous samples UPcAm, UPmAm, PcUAm and PmUAm activated in a microwave furnace. It is most probably a consequence of higher activation temperature (by $100{ }^{\circ} \mathrm{C}$ ) in conventional heating. Under the effect of high temperature and potassium carbonate, a considerable part of nitrogen groups incorporated into carbonaceous structure during the reaction with urea (at precursor or char stage) underwent decomposition or transformation to more thermally stable nitrogen species, e.g. pyridinium (N-6), pyrrole (N-5) or quaternary nitrogen (N-Q). It should be noted that urea turned out less effective $\mathrm{N}$-reagent than the mixture of ammonia and air at the ratio of 1:3. According to our earlier study (Nowicki et al. 2008) activated carbons prepared via ammoxidation (simultaneous nitrogenation and oxidation of carbonaceous materials) followed by conventional physical activation with steam or chemical activation with $\mathrm{KOH}$ showed higher nitrogen content(2.6-3.8 and 0.8-2.1 wt\%, respectively), despite the higher temperature of heat treatment or more aggressive activation conditions (potassium hydroxide as the activating agent, weight ratio of reagents equal to 4:1). Therefore, in the further study, the ammoxidation process should be used (instead of urea impregnation) for the preparation of nitrogen-enriched activated carbons by means of activation with potassium carbonate using microwave heating.

The situation is quite similar as far as oxygen contribution is concerned. The samples activated in a microwave furnace show about $3 \mathrm{wt} \%$ higher $\mathrm{O}^{\text {diff }}$ content than the analogous materials obtained by conventional heating. This is most likely due to the lower activation temperature, as a result of which more oxygen functional groups, especially those of acidic nature, are preserved on the surface of the produced activated carbons. It should be also noted that despite the high temperature treatment during pyrolysis and activation processes, all the activated carbons show lower ash content (being ballast deteriorating the physicochemical and electrochemical properties) than demineralized brown coal, used for their preparation. The low content of ash in the activated carbon samples (ranging from 0.5 to $2.7 \mathrm{wt} \%$ ) follows from the fact that a considerable amount of the inorganic matter 
present in the precursor was removed in the reaction with potassium carbonate during the activation stage as well as upon washing the activated carbons with a $5 \% \mathrm{HCl}$ solution in order to remove the excess of the activating agent and side products of the activation.

The textural parameters of the activated carbon samples were determined from the measurements of the low-temperature nitrogen adsorption/desorption isotherms, performed on a Autosorb iQ surface area analyser. As follows from the results shown in Table 3, the majority of the samples have well developed surface area and porous structure with dominant micropores. The surface area of the activated carbons prepared ranges from 617 to $1117 \mathrm{~m}^{2} / \mathrm{g}$, whereas the total pore volume varies between 0.39 and $0.69 \mathrm{~cm}^{3} / \mathrm{g}$. The data presented in Table 3 also imply that the textural parameters of the materials obtained significantly depend on the variant of activation as well as on the sequence of nitrogenation, pyrolysis and activation processes. From among the samples not subjected to reaction with urea, better developed surface area of $696 \mathrm{~m}^{2} / \mathrm{g}$ and the greater total volume of pores of $0.49 \mathrm{~cm}^{3} / \mathrm{g}$ were found for sample PmAm, activated in a microwave furnace. However, more microporous nature of the structure showed PcAc sample, activated in a conventional furnace. As follows from further analysis of the data collected in Table 3, almost all nitrogen-enriched activated carbons (with the exception of PmUAm sample) are characterized by more favourable textural parameters than unmodified carbons. The most developed porous structure was determined for samples UPcAc and UPmAc, subjected to modification with urea at the stage of precursor, followed by pyrolysis (both conventional and microwave) and activation at $800{ }^{\circ} \mathrm{C}$ in a conventional furnace. The surface area of these samples only exceeded $1050 \mathrm{~m}^{2} / \mathrm{g}$ (Table 3 ). The probable reason for such a strong development of the porous structure of these samples is increased reactivity of the modified precursor, caused by the presence of great amounts of oxygen as well as nitrogen groups introduced during the reaction with urea. As mentioned earlier, during pyrolysis a significant amount of these functional groups underwent transformation to more thermally stable species, built into deeper layers of the carbon matrix. Consequently, these functional groups could react with the potassium carbonate during the activation step (as indicated by a drastic decrease in the content of nitrogen, Table 2), facilitating the activating agent penetration into the deeper layers of the carbonaceous structure, and thus leading to a greater development of the porous structure. Much less favourable textural parameters $\left(\mathrm{S}_{\mathrm{BET}} \approx 850 \mathrm{~m}^{2} / \mathrm{g}, \mathrm{V}_{\mathrm{t}} \approx 0.54 \mathrm{~cm}^{3} / \mathrm{g}\right)$ were obtained for the analogous samples UPcAm and UPmAm activated in a microwave muffle furnace. Lower efficiency of porous structure development in these samples results probably from much milder conditions of thermal treatment during the activation process-temperature $700{ }^{\circ} \mathrm{C}$, time $15 \mathrm{~min}$. This supposition is confirmed by the fact, that samples UPcAm and UPmAm are characterized by a much higher nitrogen and oxygen content than the corresponding samples activated at $800{ }^{\circ} \mathrm{C}$ for $30 \mathrm{~min}$ (see Table 2).

Interestingly, significantly worse textural parameters were determined for the activated carbons enriched in nitrogen at the char stage, especially sample PmUAm, whose surface area $\left(617 \mathrm{~m}^{2} / \mathrm{g}\right)$ and total pore volume $\left(0.42 \mathrm{~cm}^{3} / \mathrm{g}\right)$ were lower even than for the unmodified activated carbons. This situation is probably a consequence of the fact that the majority of nitrogen and oxygen species introduced upon reaction with urea were built into the surface layers of the char's grains, because of a more ordered structure of the carbonaceous matrix. As a result during the activation process, these groups could hinder the access of potassium carbonate to the deeper layers of the carbonaceous structure, which led to gasification of the surface layers of the chars and thus to less effective development of the porous structure. This assumption is to some degree confirmed by the fact that the majority of the samples enriched in nitrogen at the char stage (PUA series) are characterized by higher mesopores contribution in total pore
Table 3 Textural parameters of activated carbons

\begin{tabular}{|c|c|c|c|c|c|c|}
\hline \multirow[t]{2}{*}{ Sample } & \multicolumn{2}{|c|}{ Surface area $\left(\mathrm{m}^{2} / \mathrm{g}\right)$} & \multicolumn{2}{|c|}{ Pore volume $\left(\mathrm{cm}^{3} / \mathrm{g}\right)$} & \multirow[t]{2}{*}{$\mathrm{V}_{\mathrm{m}} / \mathrm{V}_{\mathrm{t}}$} & \multirow[t]{2}{*}{$\mathrm{D}(\mathrm{nm})$} \\
\hline & Total & Micropore & Total & Micropore & & \\
\hline PcAc & 635 & 628 & 0.391 & 0.341 & 0.87 & 2.46 \\
\hline PmAm & 696 & 639 & 0.491 & 0.355 & 0.72 & 2.82 \\
\hline UPcAc & 1053 & 1020 & 0.687 & 0.554 & 0.81 & 2.61 \\
\hline UPcAm & 867 & 848 & 0.542 & 0.458 & 0.85 & 2.50 \\
\hline UPmAc & 1117 & 1089 & 0.676 & 0.589 & 0.87 & 2.41 \\
\hline UPmAm & 883 & 855 & 0.534 & 0.462 & 0.86 & 2.42 \\
\hline PcUAc & 891 & 879 & 0.546 & 0.477 & 0.87 & 2.45 \\
\hline PcUAm & 690 & 665 & 0.483 & 0.362 & 0.75 & 2.80 \\
\hline PmUAc & 810 & 776 & 0.514 & 0.423 & 0.82 & 2.54 \\
\hline PmUAm & 617 & 583 & 0.421 & 0.321 & 0.76 & 2.73 \\
\hline
\end{tabular}

$\mathrm{V}_{\mathrm{m}} / \mathrm{V}_{\mathrm{t}}$ : micropore contribution 
volume as well as wider average pore diameter, than the analogous carbons modified at the precursor stage (UPA series), in particular samples PcUAm and PmUAm. Unfortunately, the textural parameters of the samples described in this study are significantly less favourable than for the analogous carbons obtained by ammoxidation and chemical activation of brown coal with $\mathrm{KOH}$, in case of which the surface area varied from 2292 to $3181 \mathrm{~m}^{2} / \mathrm{g}$ (Nowicki et al. 2008). It is most probably a consequence of lower reactivity of potassium carbonate in comparison to potassium hydroxide, as well as lower weight ratio of reagents (2:1) used during this study. Worse textural parameters of discussed activated carbons may be also related to bigger grains size of the starting brown coal, which was $0.5 \mathrm{~mm}$. Therefore, further studies are needed to optimise the parameters of activation to get activated carbons of better textural properties, especially in case of samples activated in microwave furnace.
In order to characterize the chemical properties of the surface of the activated carbons obtained (unmodified and $\mathrm{N}$-doped), the contents of the surface functional groups of acidic and basic character as well as $\mathrm{pH}$ were measured. The data presented in Figs. 4 and 5 imply that the acidicbasic character of the surface depends first of all on the variant of heating applied during pyrolysis and activation processes. The second factor influencing the acid-base properties of carbonaceous materials prepared (however to a lesser extent) is the sequence of the processes of nitrogen introduction, pyrolysis and activation. As shown, the $\mathrm{pH}$ value of the activated carbons varies in a fairly wide range from 4.70 to 7.37 , however, much higher $\mathrm{pH}$ values are achieved by the samples obtained as a result of activation in a conventional furnace. The biggest difference in this respect (by 1.98) was noted for samples UPmAc and UPmAm, while the most-similar $\mathrm{pH}$ values (6.11 and
Fig. $4 \mathrm{pH}$ value of activated carbons

Fig. 5 The content of surface functional groups for activated carbons
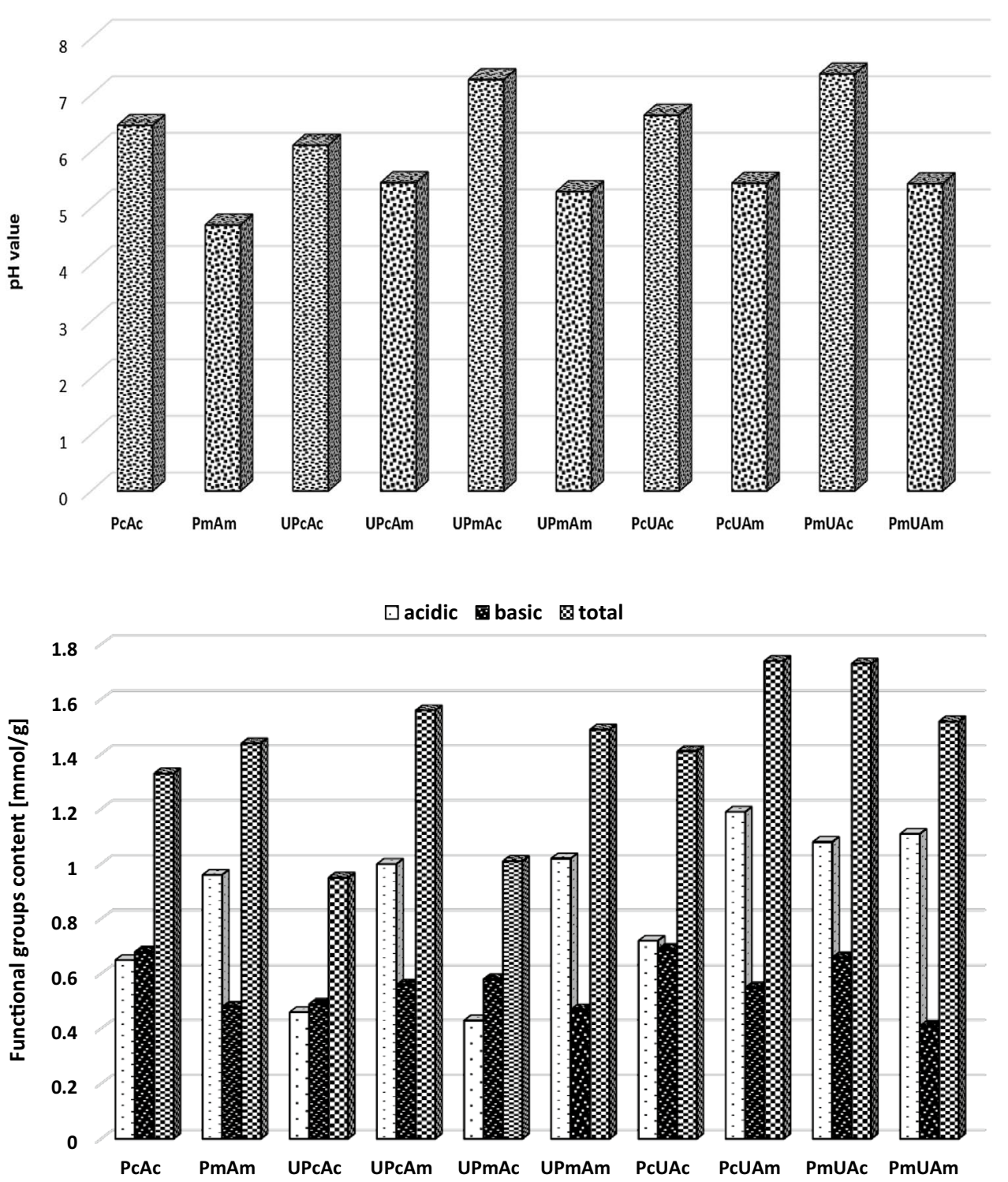
5.45, respectively) show the analogous carbons UPcAc and UPcAm.

The greatest amount of the functional species (over $1.70 \mathrm{mmol}$ per gram of activated carbon) was found on the surface of samples PcUAm and PmUAc, subjected to the reaction with urea after the pyrolysis step, while the lowest (about $1 \mathrm{mmol} / \mathrm{g}$ ) on samples UPcAc and UPmAc enriched in nitrogen at the precursor stage. According to the data from Fig. 5, the activated carbons prepared differ significantly in the content of acidic and basic groups. The samples activated in a conventional furnace (Ac) show intermediate acid-base character of the surface. The exception is sample PmUAc, which, like all the carbons activated in a microwave furnace (Am), show a distinct predominance of acidic groups. These differences most probably result from different thermal conditions of the activation process. Higher temperature $\left(800^{\circ} \mathrm{C}\right)$ used during conventional activation favours formation of a greater amount of basic functional groups, and simultaneously causes a decomposition of the acidic groups. Milder conditions of thermal treatment applied during activation in a microwave furnace $\left(700^{\circ} \mathrm{C}, 15 \mathrm{~min}\right)$ allowed preservation of a much larger number of acidic groups, especially in the nitrogen-enriched activated carbons. The greatest dominance of acidic functional surface groups was noted for sample PmUAm, which has almost three times more acidic groups $(1.11 \mathrm{mmol} / \mathrm{g})$ than basic ones $(0.41 \mathrm{mmol} / \mathrm{g})$. In turn, the greatest prevalence of groups of basic character was observed in sample UPmAc, containing $0.43 \mathrm{mmol} / \mathrm{g}$ of acidic groups and $0.58 \mathrm{mmol} / \mathrm{g}$ of basic groups. Based on the comparison of the obtained data with the results of our earlier studies (Nowicki et al. 2008), it can be concluded that the samples activated with potassium carbonate show an intermediate acidic-basic nature of the surface, between the materials chemically activated with $\mathrm{KOH}$ (characterised by great prevalence of acidic groups) and the samples physically activated with steam, for which a dominance of basic functional groups is observed.

\subsection{Methylene blue adsorption}

The data presented in Table 4 as well as in Figs. 6 and 7 clearly illustrate a significant effect of the variant of activation and nitrogen doping on the sorption abilities of activated carbons toward methylene blue (MB). From among the samples unmodified with nitrogen, more effective adsorbent against the above-mentioned organic dye proved to be sample PmAm (obtained by microwave assisted pyrolysis and activation), whose sorption capacity was by $31.7 \mathrm{mg} / \mathrm{g}$ higher than for analogous sample PcAc, obtained via conventional heat treatment. Most probably it is related to its better developed surface area as well as a considerable higher mesopores contribution in its porous structure (see Table 3), whose presence favours the sorption of compounds with large particle sizes.

As mentioned above, introduction of nitrogen functional groups into the activated carbons structure significantly improves their sorption properties toward organic pollutants. However, it should be emphasized that more effective adsorbents proved to be the carbons enriched in nitrogen at the precursor stage, especially that activated at $800{ }^{\circ} \mathrm{C}$ in a conventional furnace. The highest efficiency in methylene blue removal from water solution show samples UPmAc, UPcAc and PcUAc, whose maximum adsorption capacities were $348.4 ; 316.5$ and $308.6 \mathrm{mg} / \mathrm{g}$, respectively. It is most probably a consequence of their well-developed surface area $\left(891-1117 \mathrm{~m}^{2} / \mathrm{g}\right)$ and total pore volume $\left(0.546-0.687 \mathrm{~cm}^{3} / \mathrm{g}\right)$ as well as prevalence of basic functional groups on the surface. For the other samples (characterized by less favourable textural parameters) an increase in the sorption capacity in comparison to corresponding unmodified carbons is much lower and ranges from $34.4 \mathrm{mg} / \mathrm{g}$ for sample PmUAm
Table 4 Adsorption isotherms constants for the adsorption of methylene blue onto the activated carbons at $25 \pm 1^{\circ} \mathrm{C}$

\begin{tabular}{|c|c|c|c|c|c|c|c|}
\hline \multirow[t]{2}{*}{ Sample } & \multicolumn{4}{|l|}{ Langmuir } & \multicolumn{3}{|l|}{ Freundlich } \\
\hline & $\mathrm{q}_{\mathrm{e}}(\mathrm{mg} / \mathrm{g})$ & $\mathrm{K}_{\mathrm{L}}(\mathrm{L} / \mathrm{mg})$ & $\mathrm{R}^{2}$ & $\mathrm{R}_{\mathrm{L}}$ & $\mathrm{K}_{\mathrm{F}}(\mathrm{mg} / \mathrm{g})$ & $\mathrm{R}^{2}$ & $1 / \mathrm{n}$ \\
\hline PcAc & 57.2 & 51.4 & 0.9999 & $0.00194-0.00043$ & 53.3 & 0.6684 & 0.0287 \\
\hline PmAm & 88.9 & 93.7 & 0.9999 & $0.00213-0.00018$ & 86.2 & 0.4287 & 0.0113 \\
\hline UPcAc & 316.5 & 63.2 & 0.9999 & $0.00158-0.00009$ & 286.7 & 0.9022 & 0.0485 \\
\hline UPcAm & 230.9 & 16.6 & 0.9976 & $0.00597-0.00046$ & 191.6 & 0.9612 & 0.0771 \\
\hline UPmAc & 348.4 & 143.5 & 0.9998 & $0.00070-0.00004$ & 335.6 & 0.9068 & 0.0151 \\
\hline UPmAm & 234.7 & 26.6 & 0.9992 & $0.00374-0.00029$ & 198.9 & 0.9471 & 0.0742 \\
\hline PcUAc & 308.6 & 32.4 & 0.9997 & $0.00308-0.00017$ & 276.5 & 0.9018 & 0.0391 \\
\hline PcUAm & 175.7 & 28.4 & 0.9998 & $0.00350-0.00032$ & 151.6 & 0.9101 & 0.0567 \\
\hline PmUAc & 262.4 & 127.0 & 0.9998 & $0.00079-0.00005$ & 243.2 & 0.9415 & 0.0315 \\
\hline PmUAm & 123.3 & 8.81 & 0.9991 & $0.01122-0.00142$ & 96.4 & 0.8847 & 0.0934 \\
\hline Norit $^{\circledR} \mathrm{SX} 2^{\mathrm{a}}$ & 161.3 & 15.50 & 0.9999 & $0.00641-0.00059$ & 143.3 & 0.7384 & 0.0372 \\
\hline
\end{tabular}

${ }^{\mathrm{a} C o m m e r c i a l}$ activated carbon 
Fig. 6 Adsorption isotherms of methylene blue onto activated carbons obtained via conventional activation

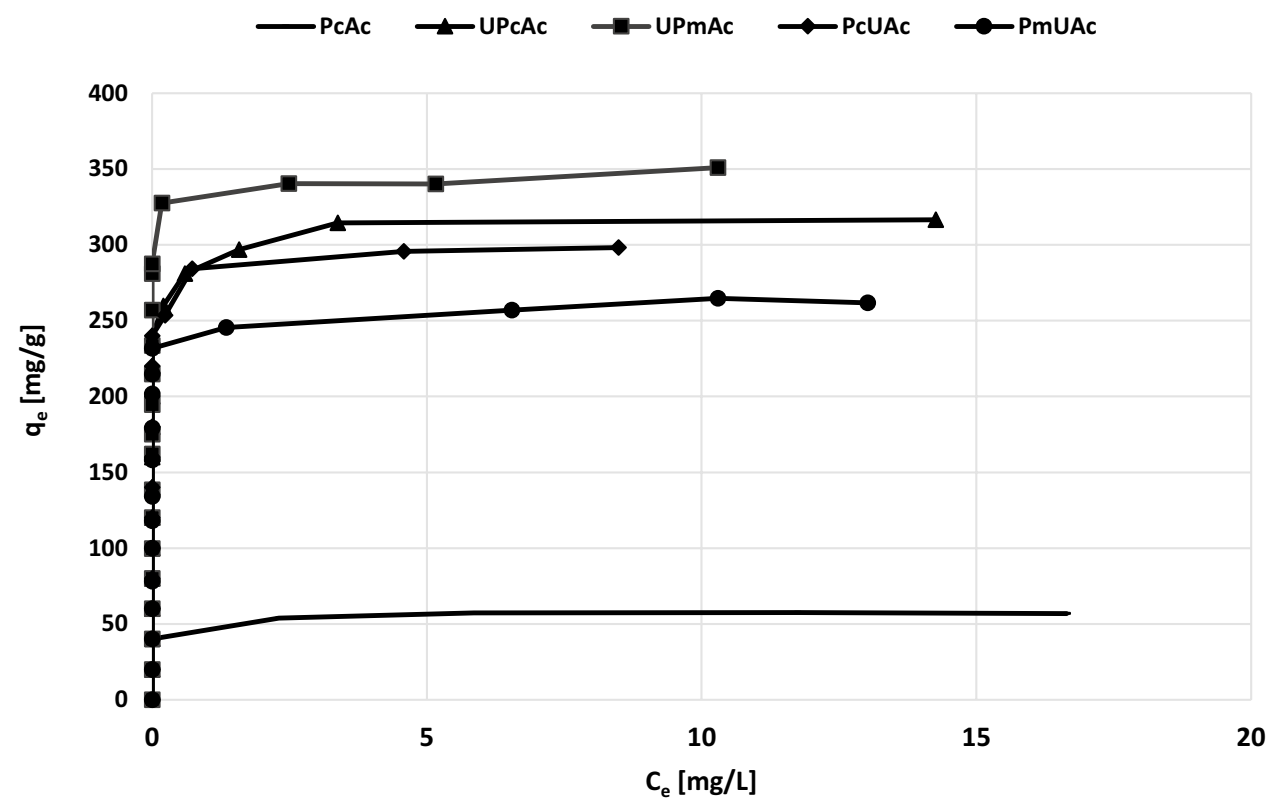

Fig. 7 Adsorption isotherms of methylene blue onto activated carbons obtained via microwave assisted activation

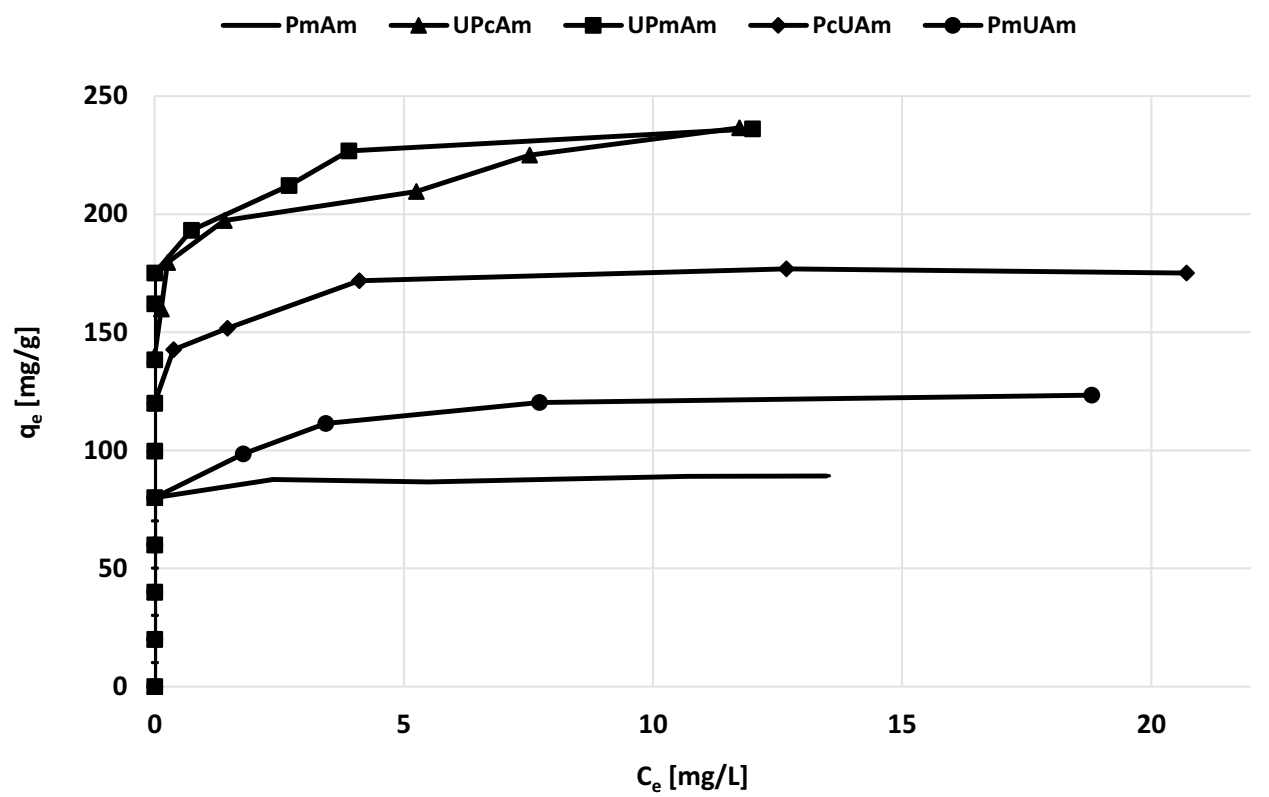

to $205.2 \mathrm{mg} / \mathrm{g}$ for sample PmUAc. However, it should be emphasized that the sorption capacities obtained for the majority of nitrogen-enriched carbons exceed significantly the sorption capacity of commercial micro/mesoporous activated carbon-Norit ${ }^{\circledR} \mathrm{SX} 2(161.3 \mathrm{mg} / \mathrm{g})$, which is very often used for water purification and decolourisation.

According to the equilibrium adsorption isotherms of methylene blue presented in Figs. 6 and 7, the amount of adsorbed dye increases significantly with increasing initial concentration of MB in water solution, until saturation. It suggest that at low methylene blue concentrations its adsorption on the activated carbons surface is rather accidental. At higher MB concentrations the active centres present on the adsorbents surface can be completely occupied by dye molecules and the surface as well as the porous structure of the activated carbons is fully saturated. As the shape of the majority of isotherms is smooth and single, it may be also supposed that we observe a monolayer coverage of the adsorbents surface with the dye molecules.

To investigate the interaction of adsorbate molecules and adsorbent surface, two well-known models, 
the Freundlich and Langmuir isotherms, were applied. According to the data collected in Table 4, the Langmuir isotherm fits the experimental data more accurately than the Freundlich isotherm, as evidenced by the high value of the correlation coefficient varying between 0.9976 and 0.9999 . Thus, according to the linear regression method, the methylene blue uptake is most probably realised as the monolayer coverage of the activated carbon surface with the dye particles. The character of the Langmuir isotherms can be also described by a separation factor $\left(\mathrm{R}_{\mathrm{L}}\right)$, which informs about the nature of the adsorption process. For all the activated carbons under investigation, the values of separation factor $\left(R_{L}\right)$ vary in the range of $0-1$, which indicates that the adsorption of methylene blue is favourable. Moreover, the values of $\mathrm{R}_{\mathrm{L}}$ factor decrease with increasing initial MB concentration in water solution, which indicates that the sorption of this organic dye is more favourable at higher concentrations. As follows from further analysis of the data presented in Table 4, for all the activated carbons prepared the value of the slope $1 / \mathrm{n}$ (a measure of surface heterogeneity and of adsorption intensity) ranges between 0.0113 and 0.0934 , which suggests that the adsorption conditions are favourable (methylene blue molecules has free access to the porous structure of activated carbons) as well as indicates a very high heterogeneity of the adsorbents surface.

\subsection{Electrochemical study}

The electrochemical performance of activated carbon as electrode material for electrochemical double layer capacitors have been studied. The cycling voltammetry characteristics are presented in Figs. 8, 9, 10a, b. Only curves recorded at 1 and $100 \mathrm{mV} / \mathrm{s}$ scan rates are included in this paper. At low scan rates $\mathrm{CV}$ curves were close to the rectangular shape. The values of specific capacitances calculated from CV technique were placed in Table 5. The highest value of capacitance was recorded for UPmAc $(86 \mathrm{~F} / \mathrm{g})$, whereas the lowest capacitance was obtained for PcAc carbon (only $5 \mathrm{~F} / \mathrm{g}$ ). The EDLC systems based on studied carbons show typical resistive behaviour with much worse charge propagation at highest scan rate $(100 \mathrm{mV} / \mathrm{s})$. Pseudocapacitance from faradaic processes was not observed. Any additional distortions at $\mathrm{CV}$ curves are related only to electrostatic charge storage on carbon surface. In Figs. 8, $9,10 \mathrm{c}$ frequency response graphs have been shown. The calculated capacitances at the lowest frequency $(1 \mathrm{mHz})$ have been placed in Table 5. The EIS technique provides the similar data to $\mathrm{CV}$. The maximum capacitance was $86 \mathrm{~F} / \mathrm{g}$ for UPmAc and only $3 \mathrm{~F} / \mathrm{g}$ for PcAc carbon. The UPmAc has also the highest capacitance at $0.1 \mathrm{mHz}(10 \mathrm{~s}$ discharging time). The performance of this material was also satisfied at high frequency region even $1 \mathrm{~Hz}$. The studies also
Fig. 8 Cycling voltammetry curves $(\mathbf{a}, \mathbf{b})$, capacitance vs. frequency response plot (c) and capacitance values at different charge/discharge current rates (d) for PcAc (green) and PmAm (red) carbons. (Color figure online) (a)

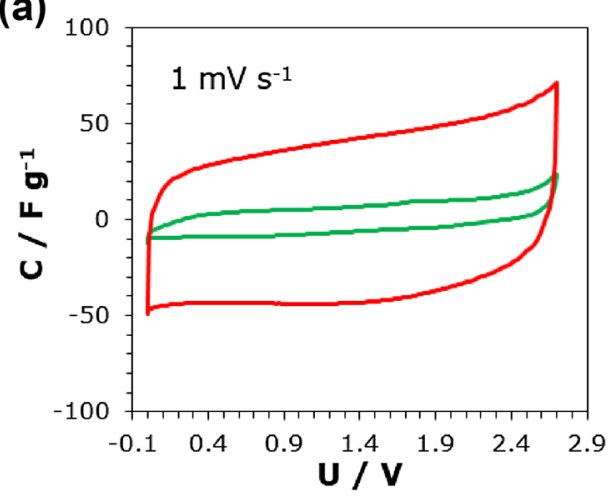

(c)

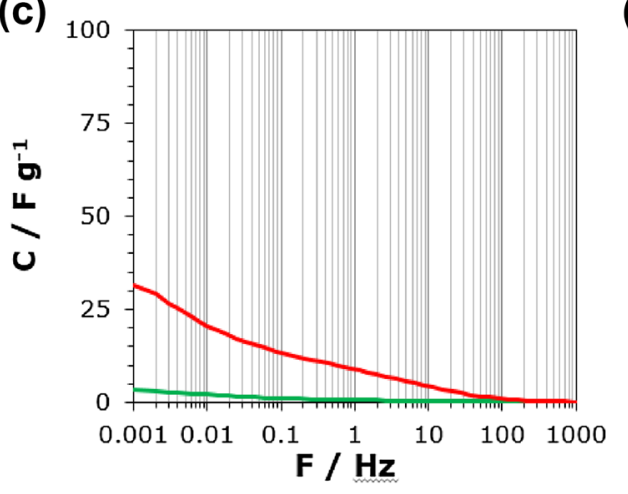

(b)

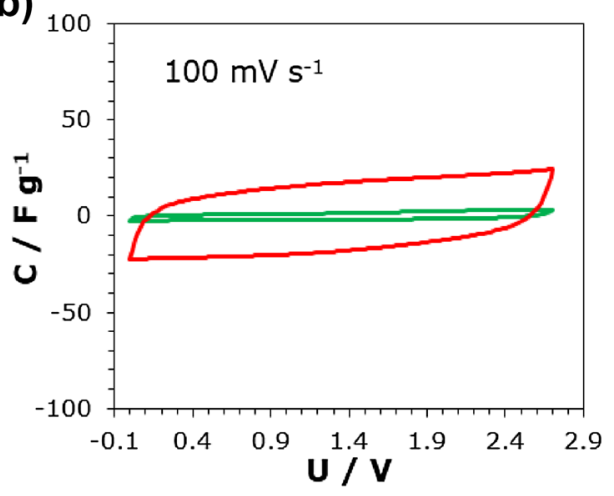

(d)

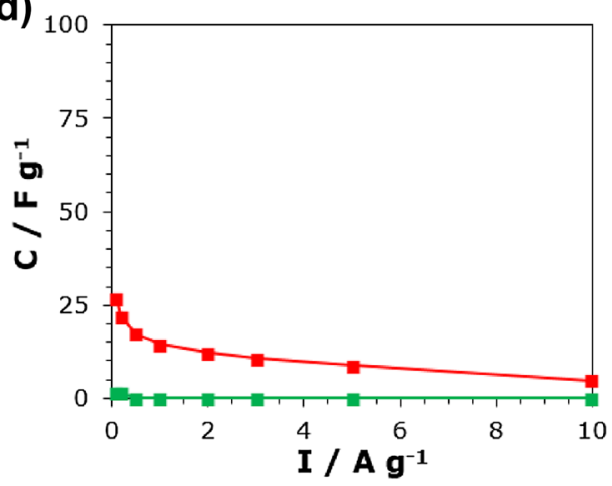


Fig. 9 Cycling voltammetry curves $(\mathbf{a}, \mathbf{b})$, capacitance vs. frequency response plot (c) and capacitance values at different charge/discharge current rates (d) for UPcAc (green); UPcAm (blue); UPmAc (red); UPmAm (grey) carbons. (Color figure online)
Fig. 10 Cycling voltammetry curves $(\mathbf{a}, \mathbf{b})$, capacitance vs. frequency response plot (c) and capacitance values at different charge/discharge current rates (d) for PcUAc (green); PcUAm (blue); PmUAc (red); PmUAm (grey) carbons. (Color figure online)
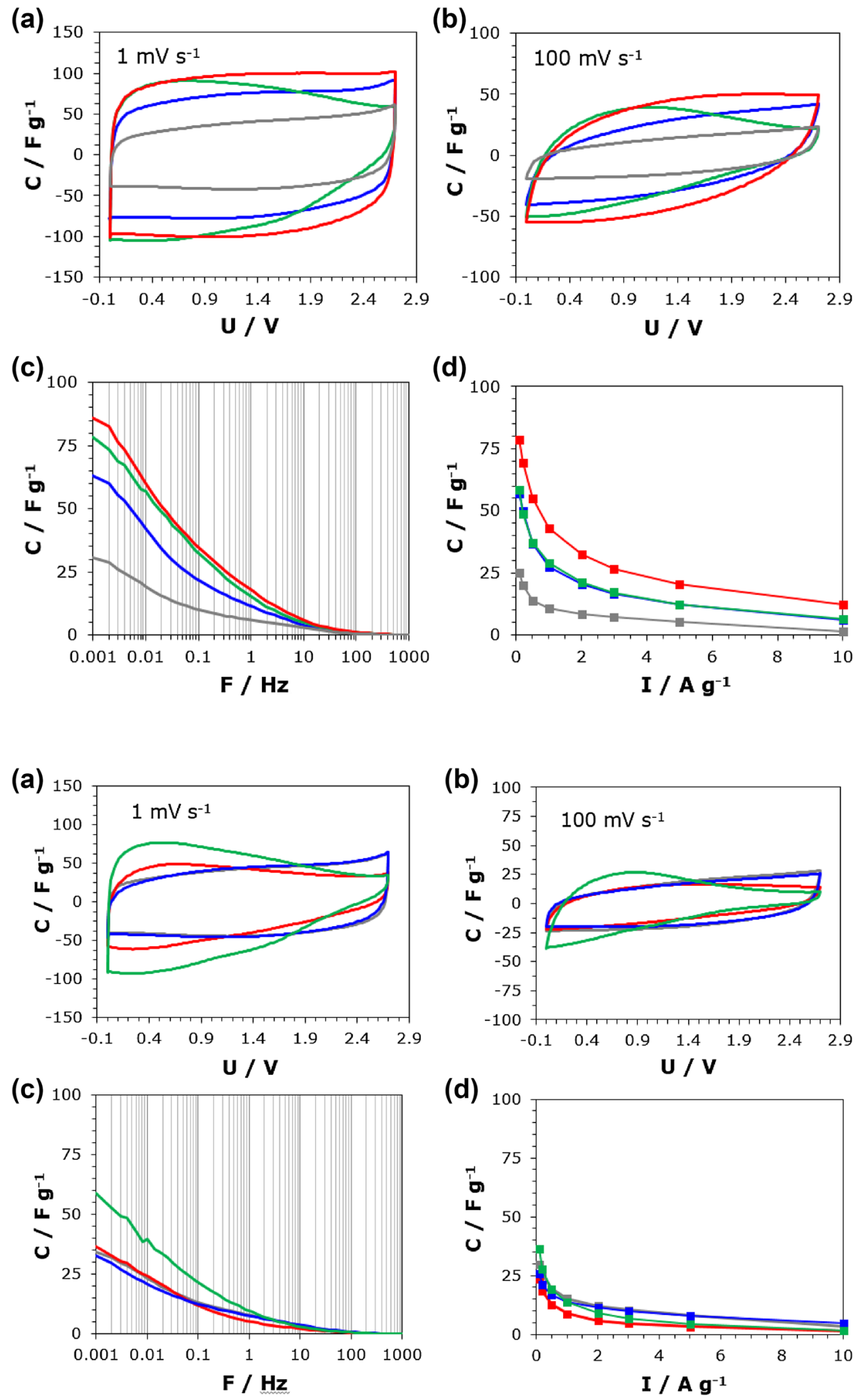

showed that the charge storage ability decreased dramatically for frequencies higher than $10 \mathrm{~Hz}$ for all tested carbons. Figures 8, 9 and 10d show the dependence of specific capacitances from current density using galvanostatic charge/discharge method. Tests have been carried out at current loads from 0.1 to $10 \mathrm{~A} / \mathrm{g}$. The specific capacitance 
Table 5 Carbons capacitances in EDLC system

\begin{tabular}{llcc}
\hline Sample & CV $(1 \mathrm{mV} / \mathrm{s})$ & EIS $(1 \mathrm{mHz})$ & GCD $(1 \mathrm{~A} / \mathrm{g})$ \\
\hline PcAc & 5 & 3 & 0 \\
PmAm & 37 & 31 & 15 \\
UPcAc & 74 & 78 & 29 \\
UPcAm & 67 & 63 & 27 \\
UPmAc & 86 & 86 & 43 \\
UPmAm & 36 & 31 & 11 \\
PcUAc & 54 & 59 & 14 \\
PcUAm & 38 & 33 & 14 \\
PmUAc & 37 & 37 & 9 \\
PmUAm & 38 & 33 & 15 \\
\hline
\end{tabular}

decreases with the increasing current density. The same relationship was observed in other papers (Wasiński et al. 2014, 2017). The specific capacitance values for EDLC system based on UPmAc and PcAc carbons at $0.1 \mathrm{~A} / \mathrm{g}$ current density were $78.5 \mathrm{~F} / \mathrm{g}$ and less than $2 \mathrm{~F} / \mathrm{g}$, respectively. The data for the $1 \mathrm{~A} / \mathrm{g}$ current density were collected in Table 5 . As seen, the specific capacitances decrease to $15 \mathrm{~F} / \mathrm{g}$ or less for most investigated carbons. However, UPmAc, UPcAm and UPcAc carbons achieved more than $12 \mathrm{~F} / \mathrm{g}$ even for $5 \mathrm{~A} / \mathrm{g}$ current density. At the highest current density $(10 \mathrm{~A} / \mathrm{g})$ the capacitances decrease to $10 \mathrm{~F} / \mathrm{g}$ for UPmAc and even lower for other tested carbons.

Only UPmAc carbon shows good performance as electrode of EDLC system. For other studied samples the charge propagation and rate capability were average or poor. This behaviour is attributed to low specific surface area of synthesized carbons. The carbon synthesis route needs optimization in terms of time and temperature of pyrolysis and activation process and the amount of urea. Generally, the incorporation of nitrogen before pyrolysis and activation processes resulted in carbons with higher specific surface area, thus, greater specific capacitance in EDLC system could be obtained. Also, the microwave assisted pyrolysis is desirable and leads to carbon materials with better electrochemical performance whereas activation process should be conducted conventionally.

\section{Conclusions}

The above presented and discussed results have shown that the application of microwave and conventional heating in preparation of nitrogen-doped activated carbons from brown coal allows producing a wide gamut of carbonaceous adsorbents with very different physicochemical properties. Depending on the procedure of activation, the final products were micro/mesoporous activated carbons of welldeveloped porous structure, showing acidic (microwave heating) or intermediate (conventional heating) acid-base character of the surface as well as very diverse content of nitrogen functional groups varying from 1.0 to $5.6 \mathrm{wt} \%$. The results obtained during the adsorption tests have proved that introduction of nitrogen functional groups into carbonaceous structure led to activated carbons with very good sorption capacity toward methylene blue, reaching $350 \mathrm{mg} / \mathrm{g}$. Unfortunately, the electrochemical tests have shown, that only sample UPmAc shows good performance as electrode material of EDLC system (maximum capacitance $86 \mathrm{~F} / \mathrm{g}$ ), so the carbon synthesis route needs optimization in terms of textural parameters and the amount of nitrogen introduced into carbon matrix.

Acknowledgements Following research was financially supported by the grant MINIATURA 1 DEC-2017/01/X/ST5/00421 funded by National Science Centre, Poland.

Open Access This article is distributed under the terms of the Creative Commons Attribution 4.0 International License (http://creativeco mmons.org/licenses/by/4.0/), which permits unrestricted use, distribution, and reproduction in any medium, provided you give appropriate credit to the original author(s) and the source, provide a link to the Creative Commons license, and indicate if changes were made.

\section{References}

Boehm, H.P.: Some aspects of the surface chemistry of carbon blacks and other carbons. Carbon 32(5), 759-769 (1994)

Boehm, H.P., Diehl, E., Heck, W., Sappok, R.: Surface oxides of carbon. Angew. Chem. Int. Edit. Engl. 3, 669-677 (1964)

Boudou, J.P., Parent, P., Suarez-Garcia, F., Vilar-Rodil, S., MartinezAlonso, A., Tascon, J.M.D.: Nitrogen in aramid-based activated carbon fibers by TPD, XPS and XANES. Carbon 44, 2452-2462 (2006)

Chen, W.C., Wen, T.C., Teng, H.: Polyaniline-deposited porous carbon electrode for supercapacitor. Electrochim. Acta 48, 641-649 (2003)

Gholidoust, A., Atkinson, J.D., Hashisho, Z.: Enhancing $\mathrm{CO}_{2}$ adsorption via amine-impregnated activated carbon from oil sands coke. Energy Fuels 31(2), 1756-1763 (2017)

Grzybek, T., Klinik, J., Motak, M., Papp, H.: Nitrogen-promoted active carbons as catalytic supports 2 . The influence of $\mathrm{Mn}$ promotion on the structure and catalytic properties in SCR. Catal. Today 137, 235-241 (2008)

Hayashi, J., Yamamoto, N., Horikawa, T., Muroyama, K., Gome, V.G.: Preparation and characterization of high-specific-surfacearea activated carbons from $\mathrm{K}_{2} \mathrm{CO}_{3}$-treated waste polyurethane. J. Colloid Interf. Sci. 281, 437-443 (2005)

Jacob, J., Chia, L.H.L., Boey, F.Y.C.: Review thermal and non-thermal interaction of microwave radiation with materials. J. Mater. Sci. 30, 5321-5327 (1995)

Jones, D.A., Lelyveld, T.P., Mavrofidis, S.D., Kingman, S.W., Miles, N.J.: Microwave heating applications in environmental engineering-a review. Resour. Conserv. Recy. 34, 75-90 (2002)

Jurewicz, K., Pietrzak, R., Nowicki, P., Wachowska, H.: Capacitance behaviour of brown coal based active carbon modified through chemical reaction with urea. Electrochim. Acta 53, 5469-5475 (2008)

Kazmierczak-Razna, J., Nowicki, P., Pietrzak, R.: The use of microwave radiation for obtaining activated carbons enriched in nitrogen. Powder Technol. 273, 71-75 (2015) 
Kazmierczak-Razna, J., Nowicki, P., Wiśniewska, M., NosalWiercińska Pietrzak, R.: Thermal and physicochemical properties of phosphorus-containing activated carbons obtained from biomass. J. Taiwan Inst. Chem. E 80, 1006-1013 (2017)

Liang, Ch, Wei, Z., Xin, Q., Li, C.: Ammonia - treated activated carbon as support of a $\mathrm{Ru}-\mathrm{Ba}$ catalyst for ammonia synthesis. React. Kinet. Catal. Lett. 83, 39-45 (2004)

Nowicki, P., Pietrzak, R.: Effect of ammoxidation of activated carbons obtained from sub-bituminous coal on their $\mathrm{NO}_{2}$ sorption capacity under dry conditions. Chem. Eng. J. 166, 1039-1043 (2011)

Nowicki, P., Pietrzak, R., Wachowska, H.: Comparison of physicochemical properties of nitrogen-enriched activated carbons prepared by physical and chemical activation of brown coal. Energy Fuels 22, 4133-4138 (2008)

Nowicki, P., Pietrzak, R., Wachowska, H.: Influence of metamorphism degree of the precursor on preparation of nitrogen enriched activated carbons by ammoxidation and chemical activation of coals. Energy Fuels 23, 2205-2212 (2009)

Nowicki, P., Pietrzak, R., Wachowska, H.: X-ray photoelectron spectroscopy study of nitrogen-enriched active carbons obtained by ammoxidation and chemical activation of brown and bituminous coals. Energy Fuels 24, 1197-1206 (2010)

Radmacher, W., Mohrhauer, O.: Demineralizing of coal for analytical purposes. Brennstoff-Chemie 37, 353-358 (1956)

Remya, N., Lin, J.G.: Current status of microwave application in wastewater treatment-a review. Chem. Eng. J. 166, 797-813 (2011)
Seredych, M., Portet, C., Gogotsi, Y., Bandosz, T.J.: Nitrogen modified carbide-derived carbons as adsorbents of hydrogen sulfide. J. Colloid Interf. Sci. 330, 60-66 (2009)

Shirahama, N., Mochida, I., Korai, Y., Choi, K.H., Enjoji, T., Shimohara, T., Yasutake, A.: Reaction of NO with urea supported on activated carbons. Appl. Catal. B-Environ. 57, 237-245 (2005)

Sullivan, P., Moate, J., Stone, B., Atkinson, J.D., Hashisho, Z., Rood, M.J.: Physical and chemical properties of PAN-derived electrospun activated carbon nanofibers and their potential for use as an adsorbent for toxic industrial chemicals. Adsorption 18, 265-274 (2012)

Vargas, D.P., Giraldo, L., Erto, A., Moreno-Piraján, J.C.: Chemical modification of activated carbon monoliths for $\mathrm{CO}_{2}$ adsorption. J. Therm. Anal. Calorim. 114(3), 1039-1047 (2013)

Wasiński, K., Walkowiak, M., Lota, G.: Humic acids as pseudocapacitive electrolyte additive for electrochemical double layer capacitors. J. Power Sources 255, 230-234 (2014)

Wasiński, K., Nowicki, P., Półrolniczak, P., Walkowiak, M., Pietrzak, R.: Processing organic waste towards high performance carbon electrodes for Electrochemical capacitors. Int. J. Electrochem. Sci. 12, 128-143 (2017)

Zaini, M.A., Amano, Y., Machida, M.: Adsorption of heavy metals onto activated carbons derived from polyacrylonitrile fiber. J. Hazard. Mater. 180(1-3), 552-560 (2010) 